Editorial

\title{
Quality partnerships in Adapted Physical Activity
}

\section{Pauli Rintala ${ }^{1}$}

Published: $15^{\text {th }}$ November 2019

Europe and Europeans have been in important roles from early on in creating such a discipline what we call now 'Adapted Physical Activity' (APA). Even before Sir Ludwig Guttman and his successful development starting from Stoke Mandeville Games in the 40's, there has been physical activity for individuals with disabilities. Today we owe a great deal for our ancestors for being so courageous in developing APA movement: from rehabilitation all the way to Paralympic movement.

European scholars had also had an integral role in founding our International Federation of Adapted Physical Activity (IFAPA) back in 1973, and later its Symposium series (ISAPA) from 1977 as a forum for scientific debate within practitioners and researchers. The 22 ${ }^{\text {nd }}$ ISAPA was organized last June in Charlottesville, Virginia, USA to continue our need for dialogue and exchanging ideas in order to develop the field of APA. The next ISAPA 2021 (see www.jyu.fi/isapa2021) will be held in Jyväskylä, Finland. The theme of the symposium is "Quality partnerships in Adapted Physical Activity: Stronger together!"

European APA professionals have cooperated over the years, and have become stronger and productive in various activities including conferences. Continental congresses (European Congress in Adapted Physical Activity, EUCAPA) have been organized since 1986, mostly every even year. Next one will be in Elche, Spain October 2020 (www.eucapa2020.com) which gives another forum for debate.

Moreover, educating future professionals in different university level programs have been a very common joint activity within European colleagues. Due to the rather narrow field and a few APA-professionals in academia, it was rational to build programs which were offered in English to different nationalities. For example, the European Master's Program in APA which began in early 1990's has endured, with modifications and name changes, over decades. It is now called IMAPA, a 2-year master programme that combines the expertise of a number of universities and offers students training and expert knowledge in Adapted Physical Activity. Itis still organized in the Faculty of Movement and Rehabilitation Sciences in KU Leuven, Belgium (https://faber.kuleuven.be/eng/education/IMAPA).

Another, bachelor level training program has a long history, too. EUDAPA (European University Diploma in Adapted Physical Activity) consists of 60 credits of training, including a 30 credits, 3-month intensive APA-training in Haaga-Helia University of Applied Sciences, Vierumäki, Finland. See: http://www.haaga-helia.fi/en/education/non-degree-programmes-0/eudapa. The unique feature of the program is students from various (mostly) European countries, as well as the visiting teachers from several European countries in which European Union's ERASMUS-exchange programs between universities are utilized.

European Journal of Adapted Physical Activity wants to be a platform for exchanging ideas born in above mentioned forums, either in conferences or training programs. EUJAPA is welcoming scientific manuscripts which, advance our understanding, are well thought and justified, and written according to the scientific writing rules and guidelines. In the field of APA, we need to cooperate in order to learn and educate each other: Together we are stronger!

\section{Author affiliation}

1 Faculty of Sport and Health Sciences, University of Jyvaskyla, Jyväskylä, Finland. Pauli.rintala@jyu.fi

(C) 2019 by the authors. Submitted for possible open access publication under the terms and conditions of the Creative Commons Attribution (CC BY) license (http://creativecommons.org/licenses/by/4.0/). 